\title{
Update in Echocardiography: Chronic Thromboembolic Pulmonary Hypertension
}

\author{
Nicholas Marston, Darrin Wong and Daniel G. Blanchard* \\ University of California, San Diego, Sulpizio Cardiovascular Center-9444 Medical Center Drive, \#7411, La Jolla, CA 92093, USA
}

Chronic thromboembolic pulmonary hypertension (CTEPH) is the result of clot persistence and fibrosis in the pulmonary vasculature after acute pulmonary embolism. This condition leads to elevated pulmonary pressures and eventually right heart failure. Patients are often severely limited by exertional dyspnea and can experience significant morbidity and mortality when left untreated [1-3]. The condition is also associated with impairment of left ventricular diastolic function and filling. Pulmonary thromboendarterectomy (PTE) is currently the only curative treatment for CTEPH and greatly alters the clinical course of the disease.

Described in detail by Moser, et al. in 1987, PTE has greatly improved CTEPH-related mortality [4]. The rapid hemodynamic and echocardiographic changes following PTE have provided an ideal model for assessing the interaction between the left and right heart. While early studies focused on the right ventricular dysfunction seen in CTEPH, more recent studies have addressed the associated left ventricular (LV) dysfunction. This article highlights two of the latest echocardiographic publications in CTEPH, one which addresses right ventricular function using strain imaging, and the other which explores the role of left atrial volume in the associated LV diastolic impairment.

\section{Right Ventricular Strain in CTEPH}

The importance of the right ventricle (RV) in overall cardiac function is not fully understood, but RV function has been shown to correlate with long-term outcomes in the setting of pulmonary hypertension [5,6]. In CTEPH, increased RV afterload causes RV hypertrophy and dilation, leading to eventual RV dysfunction and failure $[7,8]$. Intervention through PTE results in improved mean pulmonary pressure, pulmonary vascular resistance, and cardiac output [9]. Many investigators have tried to identify simple echocardiographic surrogate measures of RV function, such as tricuspid annular plane systolic excursion (TAPSE) and right ventricular fractional area change (RVFAC). Although useful, these are indirect and imperfect measures of RV volume and contractility [10-15]. No simple parameters have overcome the problem of the RV's crescentic, asymmetric shape $[16,17]$.

Deformation imaging through 2-D speckle tracking strain analysis appears to be a more robust technique to assess RV function and contractility. Strain is defined as the deformation of an object by an applied external force. Thus, right heart strain can be measured as the percentage change in shortening or thickening of the RV myocardium in the longitudinal or radial dimension [13]. In the setting of pulmonary hypertension, RV longitudinal strain has been shown to be a predictor of clinical outcomes with greater prognostic power than TAPSE [18]. Furthermore, RV strain has been shown to correlate well with invasive right heart catheterization (RHC) pressures measurements in pulmonary hypertension [19]. Recently, Sunbul, et al. reported a correlation between the 6-minute walk time (6MWT) and RV strain in CTEPH patients prior to PTE. Greater 6MWT distances correlated with higher RV basal and mid-free wall strain [20]. In addition, several studies have shown that 6MWT and New York Heart Association (NYHA) class improve after PTE [21-23]. One might infer, then, that RV strain would improve after PTE as well.

This has led to interest in using strain in CTEPH as a marker for functional improvement of the RV after PTE. At 6 months post-PTE, Giusca et al. showed gradual strain improvement in the basal and midapical segments while Mauritz et al. found similar longitudinal strain improvement by cardiac magnetic resonance (CMR) imaging [24,25]. There appears to be progressive remodeling and geometric changes after PTE, which was demonstrated by Berman et al. who demonstrated a reduction in RV mass through CMR as early as 3 months after PTE [21].

Our group at UC San Diego recently studied strain imaging in the pre- and early post-PTE periods and found that RV basal strain correlated very well with preoperative PA pressure and PVR [26]. Surprisingly, though, RV strain did not improve early after PTE, despite marked reductions in PA pressure and PVR [26]. Despite the immediate decrease in RV afterload and reduction in RV size, we found an overall absolute decrease in RV strain early after PTE. This may be due to transient RV ischemia or stunning, and as a result, early postoperative RV strain cannot be used as a marker of successful PTE.

\section{LA Volume and Left Heart Dysfunction in CTEPH}

The interplay between the right and left heart in pulmonary hypertension, which was noted long before the development of PTE, is still not fully understood. Patients with pulmonary hypertension often have diminished early LV filling (the $\mathrm{E}$ wave on Doppler imaging) with a relatively preserved atrial kick (A wave.) Theories for the LV diastolic dysfunction in CTEPH (i.e., $\mathrm{E}<\mathrm{A}$ ratio) have included elevated $\mathrm{RV}$ diastolic pressures, decreased LV volume and compliance due to septal shifting, as well as true intrinsic dysfunction of the LV [27]. With the advent of PTE, it became clear that the LV diastolic "dysfunction" improved immediately with relief of RV overload [28]. This rapid recovery suggested that there was no intrinsic LV dysfunction, and later studies confirmed this concept $[15,29,30]$.

A closer look at the E/A ratio in patients with CTEPH revealed that early diastolic filling (E) was much more diminished in CTEPH than the atrial kick (A). This low LV preload was reversed by PTE, and the E wave velocity promptly increased [31]. Thus, these studies all support the theory of LV underfilling as the primary cause of LV diastolic "dysfunction" in CTEPH.

Given this, we and others have focused more on the left atrium (LA), the chamber effectively between the RV and the LV. LA volume has been identified as a prognostic marker for a variety of cardiovascular diseases, and appears to play an integral role in

*Corresponding author: Daniel G. Blanchard, Sulpizio Cardiovascular Center 9444 Medical Center Drive, \#7411, La Jolla, CA 92093, USA, Tel: (858) 657-8530; E-mail: dblanchard@ucsd.edu

Received December 23, 2014; Accepted March 30, 2015; Published April 03 2015

Citation: Marston N, Wong D, Blanchard DG (2015) Update in Echocardiography: Chronic Thromboembolic Pulmonary Hypertension. J Pulm Respir Med 5: 252. doi: 10.4172/2161-105X.1000252

Copyright: ( $) 2015$ Marston N, et al. This is an open-access article distributed under the terms of the Creative Commons Attribution License, which permits unrestricted use, distribution, and reproduction in any medium, provided the original author and source are credited. 
overall LV function [32]. The importance of LA volume in CTEPH has not been previously examined, but recent evidence suggests that RV outflow tract dimensions may actually affect left atrial filling and volume in patients with CTEPH [33]. From front to back, space within the mediastinum is limited by the sternum anteriorly and the spine posteriorly. An enlarged RV outflow tract may restrict LA expansion and thereby affect LA filling [33]. A similar phenomenon of LA volume restriction has been described in patients with large mediastinal hiatal hernias [34]. The concept of LA size limitation from spatial restriction was tested in an animal model by Hoit, et al. [35]. Dogs that underwent pericardiectomy had a significant increase in LA compliance, reservoir function, and early diastolic LV filling compared to a control group [35]. Together, these studies suggest that impaired LA filling and volume may be caused by physical restrictions within the mediastinal space.

Our group recently examined the relationship between left atrial volume (LAV) index and pulmonary artery pressure in CTEPH [36]. We found that LAV index was in the low-normal range prior to PTE (mean: $19 \mathrm{~cm} 3 / \mathrm{m} 2$ ) but increased significantly by $18 \%$ after surgery. Additionally, lower preoperative left atrial volumes were inversely associated with higher pulmonary vascular resistance $(\mathrm{R}=-$ $0.45)$, higher mean pulmonary artery pressures $(\mathrm{R}=-0.28)$, and lower cardiac outpuindexest $(\mathrm{R}=0.48)$. Increases in LAV following PTE were associated with decreased improved PVR $(\mathrm{R}=-0.36)$, higher cardiac index $(\mathrm{R}=0.41)$, and increased mitral $\mathrm{E} / \mathrm{A}$ ratio $(\mathrm{R}=0.44)$ [36]. These last two findings are especially interesting because they suggest that postoperative increases in left atrial volume lead to increased early diastolic filling and, in turn, improved LV cardiac output. Further studies should address whether this is due more to an anatomical limitation to LA volume or to LA underfilling from depressed right ventricular output.

In summary, there have been several recent advances in our understanding of atrial and ventricular function (and interaction) in CTEPH. Further studies in this area should include assessments of global and regional right ventricular strain, as well as left heart strain before and after PTE.

\section{References}

1. Fedullo P, Kerr KM, Kim NH, Auger WR (2011) Chronic thromboembolic pulmonary hypertension. Am J Respir Crit Care Med 183: 1605-1613.

2. Lang I (2010) Advances in understanding the pathogenesis of chronic thromboembolic pulmonary hypertension. Br J Haematol 149: 478-483.

3. Lang IM, Klepetko W (2008) Chronic thromboembolic pulmonary hypertension an updated review. Curr Opin Cardiol 23: 555-559.

4. Moser KM, Daily PO, Peterson K, Dembitsky W, Vapnek JM, et al. (1987) Thromboendarterectomy for chronic, major-vessel thromboembolic pulmonary hypertension. Immediate and long-term results in 42 patients. Ann Intern Med 107: $560-565$.

5. Voelkel NF, Quaife RA, Leinwand LA, Barst RJ, McGoon MD, et al. (2006) Right ventricular function and failure: Report of a National Heart, Lung, and Blood Institute working group on cellular and molecular mechanisms of right heart failure. Circulation 114: 1883-1891.

6. Champion HC, Michelakis ED, Hassoun PM (2009) Comprehensive invasive and noninvasive approach to the right ventricle-pulmonary circulation unit: state of the art and clinical and research implications. Circulation 120: 992-1007.

7. Piazza G, Goldhaber SZ (2011) Chronic thromboembolic pulmonary hypertension. N Engl J Med 364: 351-360.

8. Menzel T, Wagner S, Kramm T, Mohr-Kahaly S, Mayer E, et al. (2000) Pathophysiology of impaired right and left ventricular function in chronic embolic pulmonary hypertension: changes after pulmonary thromboendarterectomy. Chest 118: 897-903.

9. Piovella F, D'Armini AM, Barone M, Tapson VF (2006) Chronic thromboembolic pulmonary hypertension. Semin Thromb Hemost 32: 848-855.
10. Forfia PR, Fisher MR, Mathai SC, Housten-Harris T, Hemnes AR, et al. (2006) Tricuspid annular displacement predicts survival in pulmonary hypertension. Am J Respir Crit Care Med 174: 1034-1041.

11. Hinderliter AL, Willis PW 4th, Barst RJ, Rich S, Rubin LJ, et al. (1997) Effects of long-term infusion of prostacyclin (epoprostenol) on echocardiographic measures of right ventricular structure and function in primary pulmonary hypertension. Primary Pulmonary Hypertension Study Group. Circulation 95: 1479-1486.

12. Bradlow WM, Gibbs JS, Mohiaddin RH (2012) Cardiovascular magnetic resonance in pulmonary hypertension. J Cardiovasc Magn Reson 14: 6.

13. Abraham TP, Nishimura RA (2001) Myocardial strain: can we finally measure contractility? J Am Coll Cardiol 37: 731-734.

14. Blanchard DG, Malouf PJ, Gurudevan SV, Auger WR, Madani MM, et al. (2009) Utility of right ventricular Tei index in the noninvasive evaluation of chronic thromboembolic pulmonary hypertension before and after pulmonary thromboendarterectomy. J Am Coll Cardiol Img 2: 143-149.

15. Gurudevan SV, Malouf PJ, Auger WR, Waltman TJ, Madani M, et al. (2007) Abnormal left ventricular diastolic filling in chronic thromboembolic pulmonary hypertension: true diastolic dysfunction or left ventricular underfilling? J Am Coll Cardiol 49: 1334-1339.

16. Ho SY, Nihoyannopoulos P (2006) Anatomy, echocardiography, and normal right ventricular dimensions. Heart 92 Suppl 1: i2-13.

17. Kukulski T, Hübbert L, Arnold M, Wranne B, Hatle L, et al. (2000) Normal regional right ventricular function and its change with age: a Doppler myocardial imaging study. J Am Soc Echocardiogr 13: 194-204.

18. Fine NM, Chen L, Bastiansen PM, Frantz RP, Pellikka PA, et al. (2013) Outcome prediction by quantitative right ventricular function assessment in 575 patients evaluated for pulmonary hypertension. Circ Cardiovasc Imaging 6: 711-21.

19. Dambrauskaite V, Delcroix M, Claus P, Herbots L, D'hooge J, et al. (2007) Regional right ventricular dysfunction in chronic pulmonary hypertension. J Am Soc Echocardiogr 20: 1172-1180

20. Sunbul M, Kepez A, Kivrak T, Eroglu E, Ozben B, et al. (2014) Right ventricular longitudinal deformation parameters and exercise capacity: prognosis of patients with chronic thromboembolic pulmonary hypertension. Herz 39: 470475.

21. Berman M, Gopalan D, Sharples L, Screaton N, Maccan C, et al. (2014) Right ventricular reverse remodeling after pulmonary endarterectomy: magnetic resonance imaging and clinical and right heart catheterization assessment. Pulm Circ 4: 36-44.

22. Corsico AG, D'Armini AM, Cerveri I, Klersy C, Ansaldo E, et al. (2008) Longterm outcome after pulmonary endarterectomy. Am J Respir Crit Care Med 178: 419-424.

23. Ishida K, Masuda M, Tanabe N, Matsumiya G, Tatsumi K, et al. (2012) Longterm outcome after pulmonary endarterectomy for chronic thromboembolic pulmonary hypertension. J Thorac Cardiovasc Surg 144: 321-326.

24. Giusca S, Dambrauskaite V, Scheurwegs C, D'hooge J, Claus P, et al. (2010) Deformation imaging describes right ventricular function better than longitudinal displacement of the tricuspid ring. Heart 96: 281-288.

25. Mauritz GJ, Vonk-Noordegraaf A, Kind T, Surie S, Kloek JJ, et al. (2012) Pulmonary endarterectomy normalizes interventricular dyssynchrony and right ventricular systolic wall stress. J Cardiovasc Magn Reson 14: 5.

26. Marston N, Brown JP, Olson N, Auger WR, Madani MM, et al. (2014) Righ ventricular strain before and after pulmonary thromboendarterectomy in patients with chronic thromboembolic pulmonary hypertension. Echocardiography, in press

27. Louie EK, Rich S, Brundage BH (1986) Doppler echocardiographic assessment of impaired left ventricular filling in patients with right ventricular pressure overload due to primary pulmonary hypertension. J Am Coll Cardiol 8: 1298-1306.

28. Dittrich HC, Chow LC, Nicod PH (1989) Early improvement in left ventricula diastolic function after relief of chronic right ventricular pressure overload. Circulation 80: 823-830.

29. Olson N, Brown J, Kahn A, Auger W, Madani M, et al. (2010) Left ventricular strain and strain rate by speckle tracking in chronic thromboembolic pulmonary hypertension before and after pulmonary thromboendarterectomy. Cardiovascular Ultrasound 8: 43. 
30. Lumens J, Blanchard DG, Arts T, Mahmud E, Delhaas T (2010) Left ventricular underfilling and not septal bulging dominates abnormal left ventricular filling hemodynamics in chronic thromboembolic pulmonary hypertension. Am J Physiol Heart Circ Physiol 299: 1083-1091.

31. Mahmud E, Raisinghani A, Hassankhani A, Sadeghi M, Strachan G, et al (2002) Correlation of left ventricular diastolic filling characteristics with right ventricular overload and pulmonary artery pressure in chronic thromboembolic pulmonary hypertension. J Am Coll Cardiol 40: 318-324.

32. Hoit BD (2014) Left atrial size and function: role in prognosis. J Am Coll Cardio 63: 493-505

33. Kimura BJ, Parise C, Strachan GM, Auger WR, Madani MM, et al. (2013) Diminished aortic excursion in chronic thromboembolic pulmonary hypertension. Echocardiography 30: 1126-1129.
34. Naoum C, Falk GL, Ng AC, Lu T, Ridley L, et al. (2011) Left atrial compression and the mechanism of exercise impairment in patients with a large hiatal hernia J Am Coll Cardiol 58: 1624-1634.

35. Hoit BD, Shao Y, Gabel M, Walsh RA (1993) Influence of pericardium on left atrial compliance and pulmonary venous flow. Am J Physiol 264: H1781-1787.

36. Marston NA, Auger WR, Madani MM, Kimura BJ, Strachan GM, et al. (2014) Assessment of left atrial volume before and after pulmonary thromboendarterectomy in chronic thromboembolic pulmonary hypertension. Cardiovasc Ultrasound 12: 32 